\title{
BIOCONVERSION OF GLYCEROL FOR BIOETHANOL PRODUCTION USING ISOLATED ESCHERICHIA COLI
}

\section{SS1}

\author{
Sheril Norliana Suhaimi ${ }^{1}$, Lai-Yee Phang ${ }^{1 *}$, Toshinari Maeda ${ }^{2}$, Suraini Abd-Aziz ${ }^{1}$, Minato Wakisaka ${ }^{2}$, Yoshihito Shirai ${ }^{2}$, \\ Mohd Ali Hassan ${ }^{1}$
}

${ }^{1}$ Department of Bioprocess Technology, Faculty of Biotechnology and Biomolecular Sciences, Universiti Putra Malaysia, 43400 UPM Serdang, Selangor, Malaysia; ${ }^{2}$ Department of Biological Functions and Engineering, Graduate School of Life Sciences and Engineering, Kyushu Institute of Technology, 2-4 Hibikino, Wakamatsu-ku, Kitakyushu-shi, Fukuoka, 808-0196, Japan.

Submitted: September 06, 2011; Returned to authors for corrections: October 30, 2011; Approved: June 07, 2012.

\begin{abstract}
Bioconverting glycerol into various valuable products is one of glycerol's promising applications due to its high availability at low cost and the existence of many glycerol-utilizing microorganisms. Bioethanol and biohydrogen, which are types of renewable fuels, are two examples of bioconverted products. The objectives of this study were to evaluate ethanol production from different media by local microorganism isolates and compare the ethanol fermentation profile of the selected strains to use of glucose or glycerol as sole carbon sources. The ethanol fermentations by six isolates were evaluated after a preliminary screening process. Strain named SS1 produced the highest ethanol yield of $1.0 \mathrm{~mol}$ : $1.0 \mathrm{~mol}$ glycerol and was identified as Escherichia coli SS1 Also, this isolated strain showed a higher affinity to glycerol than glucose for bioethanol production.
\end{abstract}

Key words: Glycerol; anaerobic fermentation; bioethanol; Escherichia coli SS1

\section{INTRODUCTION}

Glycerol is also known as 1,2,3-propanetriol or glycerin. Glycerol has a wide range of applications, including those in the paint, cosmetic, food and pharmaceutical industries, in addition to its use as feedstock for the production of several chemicals. Glycerol can be produced by microbial fermentation and chemical synthesis (26). In addition, it is produced as a byproduct during both soap manufacturing and biodiesel production. Recently, the low price of glycerol has been reported due to an abundance of glycerol being generated from the biodiesel industry, and because of this industry's rapid growth, the glycerol generation is also expected to increase (7). Excess glycerol may subsequently result in higher biodiesel production cost if this by-product is not properly handled or disposed of (9).

In response to the increased availability of glycerine in the commercial market, the bioconversion of glycerol into valuable

*Corresponding Author. Mailing address: Department of Bioprocess Technology, Faculty of Biotechnology and Biomolecular Sciences, Universiti Putra Malaysia, 43400 UPM Serdang, Selangor, Malaysia.; E-mail: phanglaiyee@biotech.upm.edu.my 
compounds is considered to be a promising application. Many microorganisms are known to naturally utilize glycerol as their sole carbon and energy sources $(1,25)$. Valuable chemicals produced from microbial fermentation of glycerol include 1,3propanediol, dihydroxyacetone, ethanol and succinate. In this context, glycerol is used as a substitute for the traditional substrates, such as sucrose, glucose and starch, used in industrial fermentation processes (7). Glycerol has a greater degree of reduction than does sugars, and it is also cheaper and more readily available. In comparison with glucose fermentation, the almost exclusive synthesis of reduced products during glycerol fermentation reflects the highly reducible state of glycerol. Conversion of glycerol to phosphoenolpyruvate, or pyruvate, generates twice the amount of reducing equivalents than does producing pyruvate from glucose or xylose. As an example, glycerol fermentation produced ethanol and formic acid (or ethanol and hydrogen) with overall a yield of twice that of glucose fermentation since half of the glucose lost as carbon dioxide during bioconversion of glucose (9). As biodiesel is a widely accepted renewable fuel, glycerol bioconversion into valuable chemicals will further add value to the biodiesel industry (7).

There are several microorganisms capable in fermenting glycerol in anaerobic conditions, such as Klebsiella pneumonia (4, 25) Clostridium pasteurianum (3) and Enterobacter aerogenes (17). Species of Klebsiella, Citrobacter, Enterobacter, Clostridium, Lactobcillus and Bacillus have been reported to convert glycerol into 1,3-propanediol (27) including several species of the Enterobacteriaceae family, such as Citrobacter freundii and Klebsiella pneumonia (6). In addition, species of Propionibacterium (5) and Anaerobiospirillum (21) have also been found to have the ability to ferment glycerol for the production of 1,3-propanediol via independent pathway. However, Clostridium and Enterobacter can metabolize glycerol through both oxidative and reductive pathways (30). Species of Escherichia coli were found to be able to ferment glycerol under appropriate conditions, i.e., acidic $\mathrm{pH}$, and with appropriate medium composition to produce bioethanol with minimum hydrogen accumulation (9).

Bioethanol, also known as ethyl alcohol, is a liquid biofuel that can be produced from several different biomass feedstocks. It is an alternative fuel because of its nature as a renewable bio-based resource and the fact that it also provides for the potential to reduce particulate emiSS1ons (11). Currently, produced bioethanol is primarily derived from sugar cane juice (8), plant oils, sugar beets, cereals, organic waste and cellulosic feedstocks (24). With regards to ethanol production from glycerol, glycerol-containing wastes discharged from biodiesel manufacturing processes were converted into hydrogen and ethanol by Enterobacter aerogenes HU101, which was isolated as high-rate hydrogen producers from methanogenic sludge (17). Also, Klebsiella planticola isolated from rumen red deer was identified as an ethanol producer in glycerol fermentation. Approximately 2 $\mathrm{g} / \mathrm{L}$ ethanol was produced with formate as a by-product; this process, however, required a long period of 42 days (18). The ethanol yield reported thus far has been low, although many microorganisms in nature have been identified as potential producers of ethanol that use glycerol as substrate. Hao et al. (12) focused on isolation of microorganisms that are able to produce 1,3-propanediol from glycerol fermentation in aerobic conditions. Unfortunately, the literature regarding the screening of potential microorganisms for bioconversion of glycerol into ethanol is limited.

This paper describes the evaluation regarding ethanol production from glycerol of the isolates obtained via several repeated screening processes using multiple media formulations. In addition, the ethanol fermentation profile of the selected strain was compared with other ethanol-producing bacteria that use glycerol and glucose, respectively.

\section{MATERIALS AND METHODS}

\section{Bacterial screening and isolation}

Soil samples and animal faeces were collected from 
surrounding environment on the campus of the University of Putra Malaysia, Serdang, Malaysia, and were used as microorganism strains sources. The ethanol-producing microorganisms were identified as bacteria with no special natural distribution. The glycerol-based agar medium was formulated using the following composition: $1 \mathrm{~g} / \mathrm{L} \mathrm{KH}_{2} \mathrm{PO}_{4}, 1$ $\mathrm{g} / \mathrm{L}\left(\mathrm{NH}_{4}\right)_{2} \mathrm{SO}_{4}, 1 \mathrm{~g} / \mathrm{L}$ yeast extract, $15 \mathrm{~g} / \mathrm{L} \mathrm{NaCl}$ and $1.5 \%$ $(\mathrm{w} / \mathrm{v})$ technical agar, $\mathrm{pH}$ 7.0. Glycerol was added as the sole carbon source to favour the growth of glycerol-utilizing bacteria while sodium chloride was added to create high salinity, as glycerol wastes have been reported to have high salt contents (17). The samples were diluted with distilled and sterilized water prior to being spread on an agar plate and incubated at $37^{\circ} \mathrm{C}$ for 24 hours. Further subculturing was carried out in the above-mentioned agar medium to obtain single colonies. Morphological characteristics were determined, and Gram staining was performed. Gram-negative isolates were preserved in $50 \%$ glycerol stock at $-80^{\circ} \mathrm{C}$ prior to anaerobic fermentation.

Anaerobic batch fermentation of screened isolates was carried out to determine the presence of ethanol as a metabolic product of the strains. A single colony of each culture was inoculated in a closed serum bottle containing $50 \mathrm{ml}$ lownutrient medium (13) and was incubated at $37^{\circ} \mathrm{C}$ for 24 hours. The ethanol content in the fermentation broth was analysed to screen the potential isolates capable of producing ethanol. Subsequently, the potential isolated strains were subjected to further fermentation using three different types of media as shown in Table 1 to select the best isolated strains with suitable medium composition for ethanol production. These media were used in previous research on fermentation of glycerol for ethanol production using different microorganisms.

Table 1. Medium composition described in literature for bioethanol production

\begin{tabular}{|c|c|c|}
\hline Media A [18] & Media B [2] & Media C [17] \\
\hline $2.9 \mathrm{~g} \mathrm{~K}_{2} \mathrm{HPO}_{4}$ & $5 \mathrm{~g} \mathrm{~K}_{2} \mathrm{HPO}_{4}$ & $7 \mathrm{~g} \mathrm{~K}_{2} \mathrm{HPO}_{4}$ \\
\hline $1.5 \mathrm{~g} \mathrm{KH}_{2} \mathrm{PO}_{4}$ & $3 \mathrm{~g} \mathrm{KH}_{2} \mathrm{PO} 4$ & $5.5 \mathrm{~g} \mathrm{KH}_{2} \mathrm{PO}_{4}$ \\
\hline $1.0 \mathrm{~g} \mathrm{NH}_{4} \mathrm{Cl}$ & $2.0 \mathrm{~g}\left(\mathrm{NH}_{4}\right)_{2} \mathrm{SO}_{4}$ & $1.0 \mathrm{~g}\left(\mathrm{NH}_{4}\right)_{2} \mathrm{SO}_{4}$ \\
\hline $0.2 \mathrm{~g} \mathrm{MgCl}_{2} \cdot 6 \mathrm{H}_{2} \mathrm{O}$ & $0.4 \mathrm{~g} \mathrm{MgSO}_{4} \cdot 7 \mathrm{H}_{2} \mathrm{O}$ & $0.25 \mathrm{~g} \mathrm{MgSO}_{4} .7 \mathrm{H}_{2} \mathrm{O}$ \\
\hline $0.1 \mathrm{~g} \mathrm{CaCl}_{2} .2 \mathrm{H}_{2} \mathrm{O}$ & $0.1 \mathrm{~g} \mathrm{CaCl}_{2} .2 \mathrm{H}_{2} \mathrm{O}$ & $0.021 \mathrm{~g} \mathrm{CaCl}_{2} .2 \mathrm{H}_{2} \mathrm{O}$ \\
\hline $4.2 \mathrm{~g} \mathrm{NaHCO}_{3}$ & $4 \mathrm{mg} \mathrm{CoCl}{ }_{2} \cdot 6 \mathrm{H}_{2} \mathrm{O}$ & $2.0 \mathrm{mg}$ nicotinic acid \\
\hline $0.1 \mathrm{~g}$ yeast extract & $2.0 \mathrm{mg}$ nicotinic acid & $0.12 \mathrm{~g} \mathrm{Na}_{2} \mathrm{MoO}_{4} .2 \mathrm{H}_{2} \mathrm{O}$ \\
\hline $10 \mathrm{ml}$ trace element solution & $2 \mathrm{~g}$ yeast extract & $0.172 \mathrm{mg} \mathrm{Na}_{2} \mathrm{SeO}_{3}$ \\
\hline $10 \mathrm{ml}$ vitamin solution & $0.5 \mathrm{~g}$ bacto peptone & $0.02 \mathrm{mg} \mathrm{NiCl}{ }_{2}$ \\
\hline \multirow[t]{4}{*}{$2 \%$ glycerol } & $0.3 \mathrm{~g}$ bacteriological meat extract & $5 \mathrm{~g}$ yeast extract \\
\hline & $2 \%$ glycerol & $5 \mathrm{~g}$ tryptone \\
\hline & & $10 \mathrm{ml}$ trace element solution \\
\hline & & $2 \%$ glycerol \\
\hline
\end{tabular}

\section{Strains Identification}

Morphological characteristics of the isolated strain were studied by performing Gram staining and a biochemical test using the Biolog GEN III Microplate following the manufacture's instructions. Next, identification of the isolated strain was carried out by 16s rRNA gene sequence analysis. The colony suspension was prepared prior to Robocycler Gradient 40 PCR (Stratagene, USA). Universal primers $63 \mathrm{f}$ (5'-CAGGCCTAACACATGCAAGTC-3') and 1387r (5'-

\section{GGGCGGTGTGTACAAGGC-3’) (Invitrogen, USA) were} used to amplify the 16s rRNA gene from the isolated strain. Then, the PCR product was analysed using agarose gel electrophoresis and purified, cloned and transformed into competent cells. The plasmid was purified using a Miniprep kit (QIAGEN, Japan), and then it was digested with a restriction enzyme, amplified using PCR and purified for sequencing using CEQ80 (Beckman Coulter, USA). The obtained nucleotide sequence was compared to the data by means of a 
BLAST search of the National Center for Biotechnology Information database (http://www.ncbi.nlm.nih.gov).

\section{Culture preparation}

The laboratory strains used in this study were Escherichia coli BL21, Escherichia coli BW25113 and Enterobacter aerogenes HU101 (kindly provided by Dr. Toshinari Maeda, KIT, Japan). All strains were grown on an agar plate and incubated at $37^{\circ} \mathrm{C}$ for 24 hours. Modified Luria-Bertani media, with a supplementation of glycerol were used (12). Each independent colony was inoculated in the flask and then incubated in a shaker incubator at $37^{\circ} \mathrm{C}$ at $120 \mathrm{rpm}$ of agitation until it reached the active state before it was used as an inoculum for fermentation. The media were prepared under non-sterile conditions, transferred into screw-capped shake flasks, sparged with nitrogen gas and then sterilized at $121^{\circ} \mathrm{C}$ for 20 minutes.

\section{Ethanol fermentation}

Fermentation media used in this experiment was created according to the method presented by Ito et al. (17) whereby pure glycerol was used as the sole carbon source. Preparation and inoculation were performed in an anaerobic chamber to maintain an anaerobic condition. The $120 \mathrm{ml}$ serum bottle was sealed with rubber and aluminium seals were used in this study, with total working volume of $50 \mathrm{ml}$. The anaerobic fermentation was carried out at $37^{\circ} \mathrm{C}$ with an agitation speed of $120 \mathrm{rpm}$. Sampling of fermentation broth was carried out by using a sterile syringe and needle. Then, the sample was subjected to analysis. Glycerol was substituted with glucose as a substrate in a subsequent comparative study. All media composition, preparation and fermentation were identical as the aforementioned method, with the exception of glucose being used as a substrate. The experiments were performed in duplicate in two different batches.

\section{Analysis}

Optical density (OD) was measured at $600 \mathrm{~nm}$ to estimate the cell growth. Fermentation broth was centrifuged to separate cells from the broth. The supernatant was then diluted and filtered through $0.2 \mu \mathrm{m}$ membranes and stored in $-20^{\circ} \mathrm{C}$ for further analysis. Ethanol was analysed using a gas chromatography GC-17A (Shimadzu, Japan) equipped with a flame ionization detector and a BP21 capillary column (25-m length $\times 0.53-\mathrm{mm}$ internal diameter $\times 0.5-\mu \mathrm{m}$ film thickness). The temperature of the injector and detector were set at $150^{\circ} \mathrm{C}$ and $200^{\circ} \mathrm{C}$, respectively. The oven temperature was initially maintained at $40^{\circ} \mathrm{C}$ for 1 minute and then increased to $130^{\circ} \mathrm{C}$ at a gradient of $20^{\circ} \mathrm{C}$ per minute. Helium was used as carrier gas with 1-propanol as the internal standard.

Glycerol was measured using a free glycerol reagent Cat. No F6428 (Sigma, USA) indicated by an increase in absorbance at $540 \mathrm{~nm}$ is directly proportional to the free glycerol concentration of the sample. Organic acid (acetic, lactic, formic, succinic, propionic, butyric and isobutyric acid) were measured using high-performance liquid chromatography equipped with Shim - pack SCR-102H (8 mm x $300 \mathrm{~mm}$ ) and CCD-6A electric conductivity detector (Shimadzu (Shimadzu, Japan). The mobile phase used was $5 \mathrm{mM}$ p-toluenesulfonate with flow rate of $0.8 \mathrm{~mL} / \mathrm{min}$. (23). Hydrogen and carbon dioxide from headspace of serum bottle were measured using gas chromatography with the thermal conductivity detector using nitrogen as a carrier gas (22).

\section{RESULTS AND DISCUSS1ON}

\section{Screening, isolation and characterization of glycerol- fermenting bacteria}

In this study, the sources of strains were the environment, soil and rumen faeces. Colonies grown on the solid agar indicated that many microorganisms are able to utilize glycerol as carbon source. Approximately 50 bacterial colonies were subsequently incubated in stab agar to screen for anaerobes, as most of the reported strains for glycerol fermentation are anaerobes and gram-negative bacteria $(3,16,29)$. Thirteen facultative anaerobes that were gram negative strains were 
obtained after several repeated screening processes. These isolates were grown in a low-nutrient medium with the addition of $20 \mathrm{~g} / \mathrm{L}$ glycerol as the major carbon source (14). Table 2 shows the ethanol production by the strains incubated anaerobically at $37^{\circ} \mathrm{C}$ for 24 hours. The ethanol production was first determined at 24 hours, and the fermentation time was prolonged until stationary phase was reached. Initially, the bacterial growth profile was determined by measuring the OD at different time interval. In addition, the OD was measured during glycerol fermentation to determine the phase of bacterial growth. The ethanol was detected in the fermentation ranging from $0.15 \mathrm{~g} / \mathrm{L}$ to $1.29 \mathrm{~g} / \mathrm{L}$ in a lownutrient medium.

Ethanol production was greatly affected by media composition and the nutrients requirement was dependent on the types of microorganisms. From preliminary study, low-nutrient medium was used in comparison to rich medium in evaluating the performance of these isolated strains to produce ethanol from glycerol. Results shows rich medium is needed to favour these isolated strains effectively fermenting glycerol for ethanol production (data not shown). Jarvis et al. (18), Barbirato et al. (2) and Ito et al. (17) reported ethanol production from glycerol using various strains in rich medium composition. Basically, the microbial growth in rich medium was better than in low-nutrient medium. The presence of nutrients and minerals in the rich medium enhanced the microbial growth and subsequently ethanol production. These isolated strains were unidentified, thus the selection of suitable media composition were performed simultaneously with the selection of ethanol-producing bacteria in this study. Therefore, the ethanol fermentation of 13 isolated strains was evaluated using these three rich medium (Table 1) designated as Media A (18), Media B (2) and Media C (17). Table 3 shows the maximum ethanol production of six selected strains namely A, B, E, SS1, S2 and 344. Maximum ethanol production varied from $0.4 \mathrm{~g} / \mathrm{L}$ to $6.5 \mathrm{~g} / \mathrm{L}$ using Media C (17). The strains grown in Media B (2) achieved similar ethanol production. However, Media A (18) was the least favourable media for both growth and ethanol production. Media formulations B (2) and C (17) were supplemented with $2-5 \mathrm{~g} / \mathrm{L}$ of yeast extract that enhanced the microbial growth (17). The glycerol was completely consumed by the microbes in the media with high yeast extract. In addition, phosphate was hypothesized as one of the factors affecting glycerol conversion, as phosphate plays an important role in buffering the $\mathrm{pH}$. Other by-products such as organic acids and hydrogen could be produced during fermentation. Strain SS1 produced highest quantity of ethanol with concentration of 6.53 $\mathrm{g} / \mathrm{L}$ using Media C. Media C described by Ito et al. (17) was used for the subsequent experiments. Previous research showed that $E$. aerogenes HU101 grown in Media C produced ethanol at 1.0 $\mathrm{mol} / \mathrm{mol}$ glycerol at optimum conditions using a packed-bed bioreactor.

SS1 was identified on the basis of the $16 \mathrm{~S}$ rRNA genes. The sequence of 16S rRNA genes was used in a BLAST search on the NCBI website, and the most similar sequences are listed in the results. The isolated strain was identified to be similar to $E$. coli with 99\% similarity (JN048662). The final result of biochemical test in Biolog GEN III Microplate showed 99\% probability of $E$. coli, which in agreement with 16s rRNA, hence this strain was named $E$. coli $\mathrm{SS} 1$ and used for further experiments.

Table 2. Ethanol production in low-nutrient medium by isolated strains

\begin{tabular}{lcc}
\hline Strain & Ethanol production at *24h $\mathbf{( g / L )}$ & Ethanol production at * $\mathbf{1 2 0 h}(\mathbf{g} / \mathbf{L})$ \\
\hline A & $0.27 \pm 0.02$ & $0.89 \pm 0.12$ \\
AX & $0.41 \pm 0.05$ & $0.39 \pm 0.04$ \\
B & $0.32 \pm 0.07$ & $0.71 \pm 0.10$ \\
E & $0.21 \pm 0.04$ & $0.92 \pm 0.16$ \\
F & $0.30 \pm 0.02$ & $0.31 \pm 0.03$ \\
SS1 & $0.41 \pm 0.12$ & $0.52 \pm 0.04$ \\
S2 & $0.27 \pm 0.18$ & $1.29 \pm 0.35$ \\
T & $0.29 \pm 0.04$ & $0.36 \pm 0.04$ \\
UASB & $0.18 \pm 0.04$ & $0.15 \pm 0.02$ \\
W & $0.26 \pm 0.06$ & $0.27 \pm 0.05$ \\
Y1 & $0.24 \pm 0.003$ & $0.24 \pm 0.002$ \\
Z & $0.31 \pm 0.02$ & $0.27 \pm 0.06$ \\
344 & $0.58 \pm 0.04$ & $0.82 \pm 0.03$ \\
\hline
\end{tabular}

*Duration of fermentation. Fermentation done in duplicate. 
Table 3. Maximum ethanol production and glycerol remained in three different types of media composition

\begin{tabular}{lccccccccc}
\hline Strain & \multicolumn{3}{c}{ Media A [18] } & & & Media B [2] & & \multicolumn{2}{c}{ Media C [17] } \\
\cline { 2 - 10 } & $\begin{array}{c}\text { Biomass } \\
(\mathbf{O D 6 0 0 n m})\end{array}$ & $\begin{array}{c}\text { Ethanol } \\
(\mathbf{g} / \mathbf{L})\end{array}$ & $\begin{array}{c}\text { Glycerol } \\
\mathbf{( g / L )}\end{array}$ & $\begin{array}{c}\text { Biomass } \\
(\mathbf{O D 6 0 0 n m})\end{array}$ & $\begin{array}{c}\text { Ethanol } \\
(\mathbf{g} / \mathbf{L})\end{array}$ & $\begin{array}{c}\text { Glycerol } \\
(\mathbf{g} / \mathbf{L})\end{array}$ & $\begin{array}{c}\text { Biomass } \\
(\mathbf{O D 6 0 0 n m})\end{array}$ & $\begin{array}{c}\text { Ethanol } \\
(\mathbf{g} / \mathbf{L})\end{array}$ & $\begin{array}{c}\text { Glycerol } \\
(\mathbf{g} / \mathbf{L})\end{array}$ \\
\hline 344 & $0.746 \pm 0.07$ & $0.77 \pm 0.07$ & $5.75 \pm 0.68$ & $1.033 \pm 0.04$ & $0.61 \pm 0.002$ & $5.51 \pm 0.38$ & $1.233 \pm 0.03$ & $0.61 \pm 0.05$ & $3.03 \pm 0.93$ \\
A & $0.492 \pm 0.08$ & $2.40 \pm 0.16$ & $7.73 \pm 0.25$ & $0.707 \pm 0.03$ & $2.81 \pm 0.23$ & $8.77 \pm 0.28$ & $0.671 \pm 0.1$ & $1.27 \pm 0.3$ & $8.94 \pm 0.29$ \\
B & $0.482 \pm 0.05$ & $1.74 \pm 0.26$ & $8.76 \pm 0.33$ & $0.450 \pm 0.03$ & $1.98 \pm 0.38$ & $7.05 \pm 0.68$ & $0.518 \pm 0.1$ & $2.51 \pm 0.2$ & $4.43 \pm 0.63$ \\
E & $0.677 \pm 0.05$ & $1.26 \pm 0.11$ & $9.31 \pm 0.50$ & $0.570 \pm 0.03$ & $1.64 \pm 0.03$ & $8.94 \pm 0.14$ & $0.782 \pm 0.03$ & $1.59 \pm 0.26$ & $7.74 \pm 0.13$ \\
S2 & $0.558 \pm 0.06$ & $0.13 \pm 0.03$ & $5.67 \pm 0.51$ & $0.719 \pm 0.03$ & $0.19 \pm 0.02$ & $4.99 \pm 0.92$ & $1.210 \pm 0.04$ & $0.40 \pm 0.02$ & $4.21 \pm 0.94$ \\
SS1 & $0.555 \pm 0.04$ & $1.68 \pm 0.02$ & $5.71 \pm 0.85$ & $0.775 \pm 0.01$ & $5.22 \pm 0.49$ & $5.48 \pm 0.42$ & $1.204 \pm 0.04$ & $6.35 \pm 0.25$ & $4.15 \pm 0.24$ \\
\hline
\end{tabular}

\section{Ethanol fermentation profile by $E$. coli SS1}

The ethanol fermentations of isolated E. coli SS1 using two different substrates, glucose and glycerol, were compared. Glucose is traditional substrate mainly used for ethanol fermentation (7). As shown in Fig. 1, the biomass growth reached stationary phase after 24 hours of incubation; with maximum optical density of $2.1 \pm 0.01$. In comparison to fermentation using glycerol (Fig. 2), the biomass growth achieved stationary phase after 12 hours of incubation, with maximum optical density of $1.92 \pm 0.1$. This isolated strain demonstrates faster growth using glycerol as substrate; however the maximum biomass was lower than that in the study performed by Dharmadi et al. (9), which shows the end of the log phase at $84 \mathrm{~h}$ of incubation. Glucose consumed was $8.08 \pm 0.1 \mathrm{~g} / \mathrm{L}(40 \%)$ after 96 hours of incubation, while more than $70 \%$ of glycerol was consumed during the first 24 hours of fermentation, and it continued until the end of fermentation, leaving $1.35 \pm 0.1 \mathrm{~g} / \mathrm{L}$ of unfermented glycerol. Ethanol was produced mainly during the stationary phase of the fermentation. In this study, ethanol was produced during fermentation at $96 \mathrm{~h}$ with the maximum concentration of $0.90 \pm$ $0.14 \mathrm{~g} / \mathrm{L}$ and $9.23 \pm 0.6 \mathrm{~g} / \mathrm{L}$, from glucose and glycerol, respectively. Aside from ethanol, hydrogen was also produced during fermentation with a maximum concentration of $0.99 \pm 0.02 \mathrm{mmol}$ from glucose and $1.59 \pm 0.09 \mathrm{mmol}$ from glycerol. Minor amount of organic acids, such as succinic acid, lactic acid, acetic acid and formic acid, were detected in both fermentations.

The conversion of glycerol using isolated E. coli SS1 results in a product mixture containing ethanol as the main product in addition to hydrogen and minor amounts of acetate, succinate and formate. During fermentation, production of ethanol is preferable because one molecule of ATP is generated from each molecule of glycerol into ethanol (28). In comparison to the previous research, Dharmadi et al. (9) discovered that E. coli MG1655 convert $10 \mathrm{~g} / \mathrm{L}$ of glycerol into approximately $4.5 \mathrm{~g} / \mathrm{L}$ of ethanol anaerobically within $84 \mathrm{~h}$ of active growth, leaving $1.2 \mathrm{~g} / \mathrm{L}$ unfermented glycerol under an acidic condition with the production of $\mathrm{CO}_{2}$ from formate formation. On the other hand, Ito et al. (17) found that $E$. aerogenes HU101 is able to produce ethanol and hydrogen using biodiesel wastes containing glycerol as a carbon source. They found that an increase in glycerol will decrease the yields of hydrogen and ethanol. A $5 \mathrm{~g} / \mathrm{L}$ of glycerol was converted into $2.5 \mathrm{~g} / \mathrm{L}$ ethanol with an optimized fermentation technique using a bioreactor. Among these studies, genetically engineered strains used were able to ferment a lower amount of glycerol than that in this study. In comparison to this study, the isolated wild type strains show the capability to convert up to $20 \mathrm{~g} / \mathrm{L}$ of glycerol for the production of primarily ethanol with hydrogen as a co-product, in which can be an advantage. 


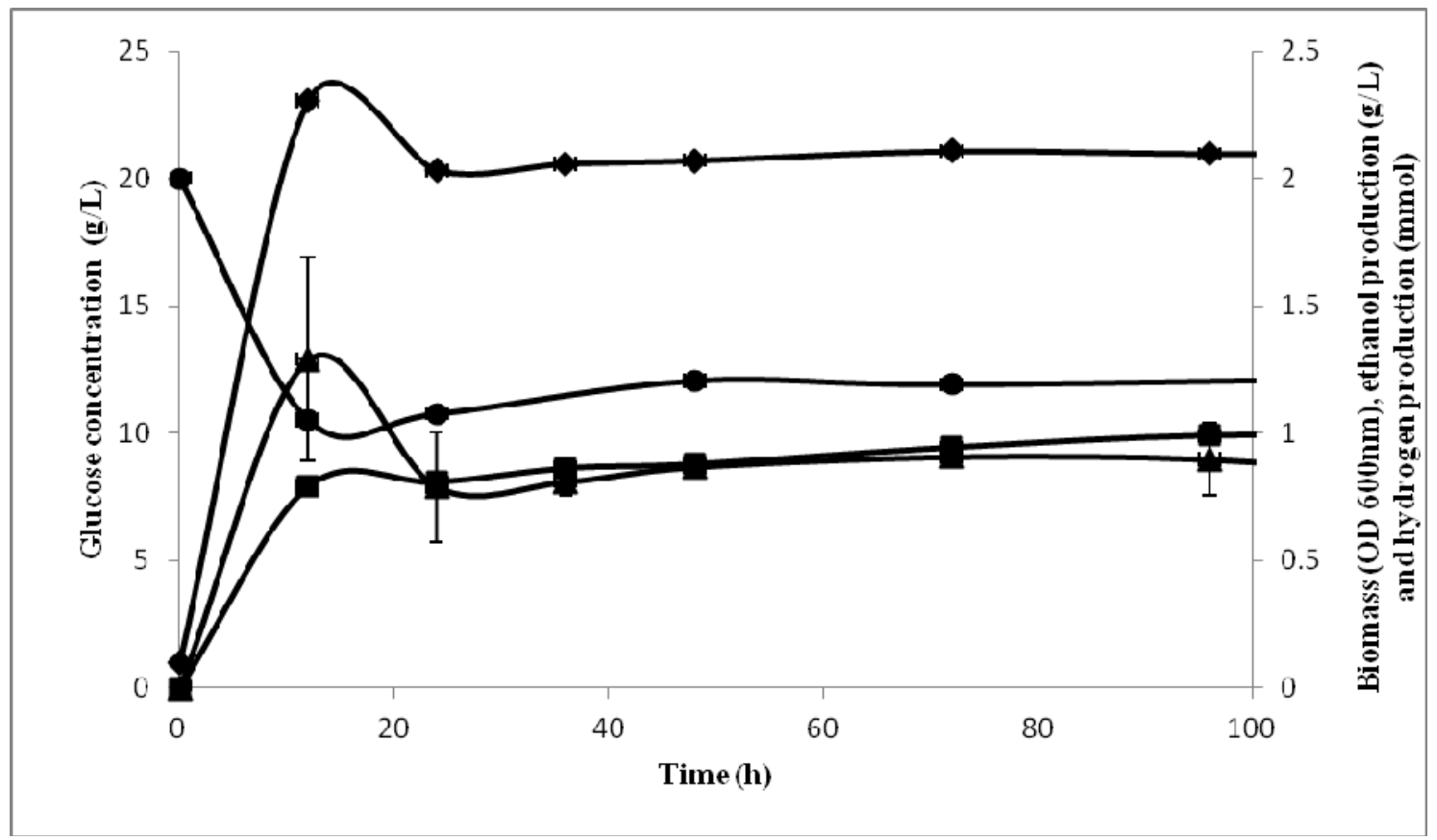

Figure 1. Ethanol and hydrogen production profile by Escherichia coli SS1 using glucose as substrate: ethanol (ロ), glucose (•), biomass OD $(\diamond)$ and hydrogen $(\boldsymbol{\Delta})$

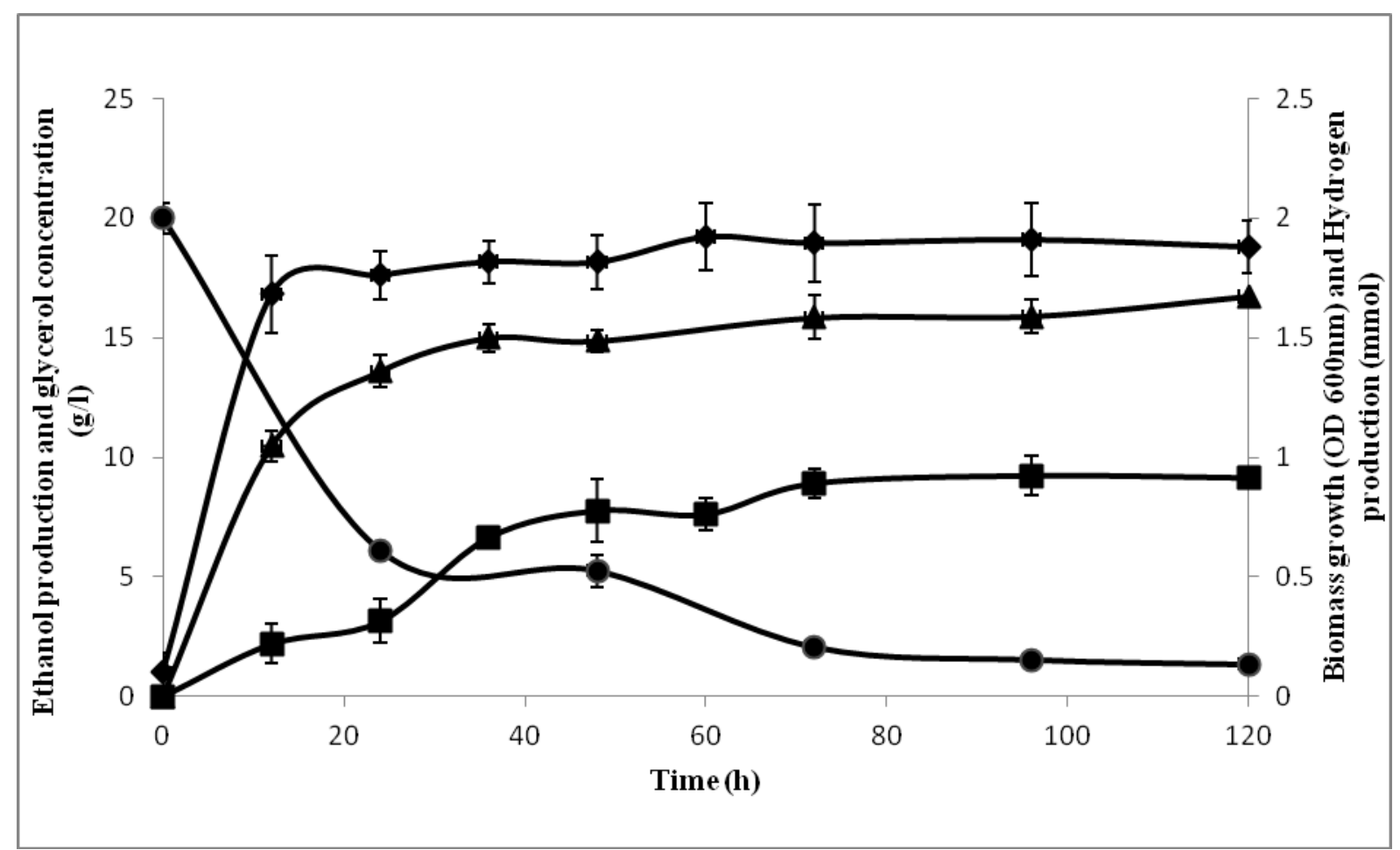

Figure 2. Ethanol and hydrogen production profile by E. coli SS1 using glycerol as substrate: ethanol (ロ), glycerol (•), biomass $(\diamond)$ and hydrogen $(\boldsymbol{\Delta})$ 


\section{Ethanol fermentation comparative study}

The ability of isolated $E$. coli $\mathrm{SS} 1$ with regards to ethanol production was compared with E. coli BL21 (laboratory strain), E. coli BW25113 $(10,15)$ and E. aerogenes HU101 (17) by using glucose (Table 4a) and glycerol (Table 4b). In this study, a $20 \mathrm{~g} / \mathrm{L}$ of glucose or glycerol were used as the initial source of carbon. In comparison to other studied strains with regards to ethanol fermentation from glucose (Table 4a), isolated $E$. coli SS1 yields lower concentrations of ethanol and hydrogen, 0.44 and $0.63 \mathrm{~mol} / \mathrm{mol}$, respectively when compared to the laboratory strain E. coli BL21, which produced greater amounts of ethanol $(0.99 \mathrm{~mol} / \mathrm{mol})$ and hydrogen $(1.43$ $\mathrm{mol} / \mathrm{mol}$ ). Strain E. coli BW25113 yields $0.37 \mathrm{~mol} / \mathrm{mol}$ of ethanol and $0.67 \mathrm{~mol} / \mathrm{mol}$ of hydrogen, whereas E. aerogenes HU101 has the lowest ethanol $(0.23 \mathrm{~mol} / \mathrm{mol})$ and hydrogen $(0.23 \mathrm{~mol} / \mathrm{mol})$ yields. Glucose was not consumed completely by $E$. coli SS1, leaving $11.92 \pm 0.1 \mathrm{~g} / \mathrm{L}$ of unfermented glucose. Similar results can be observed for other $E$. coli strains, which show low glucose consumption, of which the lowest is for the laboratory E. coli BL21 $(3.1 \pm 0.1 \mathrm{~g} / \mathrm{L})$. In contrast, E. aerogenes HU101 consumed more than $96 \%$ glucose, but this strain is not able to efficiently convert glucose into ethanol. In all studied strains, although glucose was consumed, giving similar biomass growth when compared to glycerol, little ethanol was produced. Hydrogen and minor amount of several organic acids such as succinic acid, lactic acid, acetic acid and formic acid were produced as by products during fermentation of glucose. Glucose has lower degree of reduction as compared to glycerol, and hence, lower yields were obtained. Half of the sugar is lost as carbon dioxide during the bioconversion of glucose (9). In many studies, metabolic engineering approaches have been exploited to develop strains that can effectively produce ethanol from sugar metabolism $(19,20)$.

Table 4a. Ethanol fermentation profile of E.coli SS1 (\#SS1), E.coli BL21, E.coli BW25113 and E. aerogenes HU101 using glucose $(20 \mathrm{~g} / \mathrm{L})$ as substrate

\begin{tabular}{|c|c|c|c|c|c|c|c|c|c|c|}
\hline \multicolumn{11}{|c|}{ *Composition of broth } \\
\hline \multirow[t]{2}{*}{ Strain } & \multirow{2}{*}{$\begin{array}{c}\text { Biomass } \\
\text { (OD 600nm) }\end{array}$} & \multirow{2}{*}{$\begin{array}{c}\text { Glucose } \\
(\mathrm{g} / \mathrm{L})\end{array}$} & \multirow{2}{*}{$\begin{array}{c}\text { Ethanol } \\
(\mathrm{g} / \mathrm{L})\end{array}$} & \multirow{2}{*}{$\begin{array}{c}\text { Hydrogen } \\
\text { (mmol) }\end{array}$} & \multicolumn{4}{|c|}{ Organic acids $(\mathrm{mg} / \mathrm{L})$} & \multirow{2}{*}{$\begin{array}{c}\text { Ethanol } \\
\text { yield } \\
\text { (mol/mol) }\end{array}$} & \multirow{2}{*}{$\begin{array}{c}\text { Hydrogen } \\
\text { yield } \\
\text { (mol/mol) }\end{array}$} \\
\hline & & & & & $\begin{array}{c}\text { Succinic } \\
\text { acid }\end{array}$ & $\begin{array}{l}\text { Lactic } \\
\text { acid }\end{array}$ & $\begin{array}{c}\text { Acetic } \\
\text { acid }\end{array}$ & $\begin{array}{c}\text { Formic } \\
\text { acid }\end{array}$ & & \\
\hline E. coli $\mathrm{SS} 1$ & $2.10 \pm 0.01$ & $11.92 \pm 0.1$ & $0.90 \pm 0.14$ & $0.99 \pm 0.02$ & 11.38 & 8.29 & 3.67 & 8.46 & 0.44 & 0.63 \\
\hline E. coli BL21 & $1.90 \pm 0.27$ & $16.90 \pm 0.1$ & $0.79 \pm 0.5$ & $0.86 \pm 0.2$ & 8.45 & 13.93 & 5.82 & 9.24 & 0.99 & 1.43 \\
\hline E. coli BW25113 & $1.99 \pm 0.02$ & $12.36 \pm 0.2$ & $0.72 \pm 0.2$ & $1.02 \pm 0.02$ & 14.56 & 12.47 & 4.86 & 8.53 & 0.37 & 0.67 \\
\hline E. aerogenes HU101 & $2.19 \pm 0.02$ & $0.80 \pm 0.4$ & $1.42 \pm 0.42$ & $0.85 \pm 0.03$ & 12.41 & 15.96 & 7.89 & 8.51 & 0.23 & 0.23 \\
\hline
\end{tabular}

*Fermentation at $96 \mathrm{~h}$

Table 4b. Ethanol fermentation profile of E.coli SS1, E.coli BL21, E.coli BW25113 and E. aerogenes HU101 using glycerol (20 $\mathrm{g} / \mathrm{L})$ as substrate

\begin{tabular}{|c|c|c|c|c|c|c|c|c|c|c|}
\hline \multirow{3}{*}{ Strain } & \multicolumn{10}{|c|}{ *Composition of broth } \\
\hline & \multirow{2}{*}{$\begin{array}{c}\text { Biomass } \\
\text { (OD 600nm) }\end{array}$} & \multirow{2}{*}{$\begin{array}{c}\text { Glycerol } \\
\text { (g/L) }\end{array}$} & \multirow{2}{*}{$\begin{array}{c}\text { Ethanol } \\
(\mathrm{g} / \mathrm{L})\end{array}$} & \multirow{2}{*}{$\begin{array}{c}\text { Hydrogen } \\
\text { (mmol) }\end{array}$} & \multicolumn{4}{|c|}{ Organic acids (mg/L) } & \multirow{2}{*}{$\begin{array}{c}\text { Ethanol } \\
\text { yield } \\
\text { (mol } / \mathrm{mol})\end{array}$} & \multirow{2}{*}{$\begin{array}{c}\text { Hydrogen } \\
\text { yield } \\
(\mathrm{mol} / \mathrm{mol})\end{array}$} \\
\hline & & & & & $\begin{array}{c}\text { Succinic } \\
\text { acid }\end{array}$ & $\begin{array}{c}\text { Lactic } \\
\text { acid }\end{array}$ & $\begin{array}{c}\text { Acetic } \\
\text { acid }\end{array}$ & $\begin{array}{c}\text { Formic } \\
\text { acid }\end{array}$ & & \\
\hline E. coli SS1 & $1.90 \pm 0.15$ & $1.54 \pm 0.08$ & $9.23 \pm 0.6$ & $1.67 \pm 0.07$ & 15.01 & 81.38 & 23.87 & ND & 1.00 & 0.24 \\
\hline E. coli BL21 & $1.95 \pm 0.02$ & $0.85 \pm 0.18$ & $9.50 \pm 0.67$ & $1.61 \pm 0.11$ & 3.02 & 49.17 & 9.18 & ND & 0.991 & 0.22 \\
\hline E. coli BW25113 & $1.84 \pm 0.04$ & $2.05 \pm 0.75$ & $5.33 \pm 1$ & $1.38 \pm 0.1$ & 9.55 & 78.65 & 10.95 & 15.12 & 0.592 & 0.20 \\
\hline E. aerogenes HU101 & $1.90 \pm 0.02$ & $6.61 \pm 1.13$ & $3.98 \pm 0.27$ & $1.45 \pm 0.06$ & 10.6 & 91.75 & 23.47 & ND & 0.594 & 0.28 \\
\hline
\end{tabular}


Hence, the ethanol fermentation using glycerol as substrate was examined. As described previously, glycerol is one of potential carbon source that can be fermented by several microorganisms for production of various valuable products. As shown in Table $4 \mathrm{~b}$, the ethanol yield obtained by $E$. coli $\mathrm{SS} 1$ was $1.0 \mathrm{~mol} / \mathrm{mol}$, which is comparable to that of $E$. coli BL21 (laboratory strain), with the yield of $0.991 \mathrm{~mol} / \mathrm{mol}$. Similar fermentation profile was observed in these two strains, where the amount of glycerol being consumed and ethanol produced were similar. These two strains effectively ferment glycerol for ethanol production as compared to the other strains. E. coli BW25113 and E. aerogenes HU101 produced a relatively lower amount of ethanol, with yields of 0.592 $\mathrm{mol} / \mathrm{mol}$ and $0.594 \mathrm{~mol} / \mathrm{mol}$, respectively.

In the bioconversion of glycerol, it is first converted to pyruvate, whereby pyruvate is further reduced into various organic compounds, such as ethanol. The organic compounds produced vary depending on the types of microorganism and the culture conditions. Glycerol can be converted to ethanol with co-production of either hydrogen or formate. In addition, the formate generated can also be converted completely for the production of hydrogen and carbon dioxide [7, 28]. Hence, the presence of hydrogen is expected during the fermentation of glycerol. The hydrogen yield in all studied strains were similar, and were determined to fall in the range of $0.20-0.28$ $\mathrm{mol} / \mathrm{mol}$. Aside from this, in this study, several organic acids, such as succinic acid, lactic acid and acetic acid, were detected at minor concentrations at $\mathrm{mg} / \mathrm{L}$ in the fermentation broth Different types of microorganisms produce different types of organic products including organic acids, depending on the metabolic pathways during glycerol degradation [7]. Formic acid was actually produced during the initial stage of fermentation (data not shown), whereas no formic acid was detected at the end of fermentation because it is converted into hydrogen and carbon dioxide. Despite this, a minor amount of formic acid was detected during fermentation using $E$. coli BW25113.
In comparison with all studied strains, the isolated $E$. coli SS1 produced ethanol that was approximately 2.3 - and 1.7-fold higher in concentration than did E. aerogenes HU101 and E. coli BW25113, respectively. However, in comparison to glucose, the isolated $E$. coli $\mathrm{SS} 1$ could not efficiently consume glucose $(8.08 \pm 0.1 \mathrm{~g} / \mathrm{L})$ for ethanol production. It showed that isolated $E$. coli $\mathrm{SS} 1$ has low affinity or utilizing rate to glucose in comparison to glycerol for ethanol production. Even strain E. coli BL21 able to gives similar yield in both fermentation conditions, this strain consumed only $15 \%$ of total amount of glucose used as substrate, whereas nearly all glycerol was consumed by this strain. Thus, glycerol is more preferable compared to glucose as substrate in this ethanol fermentation.

Isolated E. coli $\mathrm{SS} 1$ was obtained after several screening processes and has been compared by using three differentlycomposed media. Ethanol fermentation by isolated E. coli $\mathrm{SS} 1$ using glycerol and glucose, respectively, shows that this isolated strain has a greater capability for the production of ethanol at higher yields using glycerol than it does when using glucose as a carbon source. The results from this study show that wild-type E. coli that is locally isolated, is an effective microorganism that can be used for the conversion of glycerol into ethanol and hydrogen. In many studies related to sugar conversion, engineered E. coli is needed for conversion into valuable products. In this study, however, wild-type $E$. coli was in fact able to produce high yield of ethanol with other byproducts including hydrogen and several organic acids at minor amounts from glycerol. In addition, in the conversion of glycerol, increased yields of products can be obtained as opposed to other sugars, such as glucose [27], due to the higher degrees of reduction per carbon in glycerol than in sugars.

Despite the fact that many types of microorganisms are able to produce ethanol from various carbon sources, E. coli has been considered a potential tool in ethanol production, under consideration of its many advantages, such as rapid growth as well as its ability to maintain metabolic activity under aerobic and anaerobic conditions. Furthermore, E. coli 
can be exploited as a genetic tool that can be used to improve the production via metabolic engineering techniques. With an abundance of glycerol in nature due to the increase of biodiesel production, there is a great potential for the isolated strain $E$. coli SS1 to be used for the production of ethanol from glycerol.

\section{CONCLUSION}

The bioconversion of glycerol, instead of glucose, into ethanol by an isolated strain identified as E. coli $\mathrm{SS} 1$ is feasible. Hydrogen was produced as a co-product during ethanol fermentation using this isolated strain with full conversion for an ethanol yield. In ethanol fermentation with glycerol, isolated E. coli SS1 yielded increased amounts of ethanol and hydrogen than did E. coli BW25113 and E. aerogenes HU101 prior to optimization processes. In addition, isolated E. coli $\mathrm{SS} 1$ produced greater amount of ethanol from glycerol, whereas lower ethanol yield was obtained during fermentation with glucose as a substrate. The ethanol yield during glycerol fermentation was approximately three-fold higher than that of glucose fermentation. Thus, this isolated strain is considered as a potential glycerol-fermenting bacterium for the bioethanol industry as glycerol is a cheap and abundant resource derived from the biodiesel industry. This isolated strain may play an important role as a genetic tool for future upstream processes in bioethanol fermentation as it exhibited high similarity to $E$. coli $\mathrm{SS} 1$.

\section{REFERENCES}

1. Barbirato, F.; Bories, A. (1997). Relationship between the physiology of Enterobacter agglomerans CNCM 1210 grown anaerobically on glycerol and the culture conditions. Res. Microbiol. 148: 475-484.

2. Barbirato, F.; Himmi, E.H.; Conte, T.; Bories, A. (1998). 1,3Propanediol production by fermentation: an interesting way to valorize glycerin from the ester and ethanol industries. Ind. Crop. Prod. 7: 281289.

3. Biebl, H. (2001). Fermentation of glycerol by Clostridium pasteurianum — batch and continuous culture studies. J. Ind. Microbiol. Biotechnol.
27: $18-26$.

4. Biebl, H.; Zeng A.P.; Menzel, K.; Deckwer, W.D. (1998). Fermentation of glycerol to 1,3 propanediol and 2,3-butanediol by Klebsiella pneumoniae. Appl. Microbiol. Biotechnol. 50: 24-29.

5. Bories, A.; Himmi, E.; Jauregui, J.J.A.; Pelayo-Ortiz, C.; Gonzalez, V.A. (2004). Glycerol fermentation with Propionibacteria and optimisation of the production of propionic acid. Sci. des. Aliments. 24: 121-135.

6. Bouvet, O.M.M.; Lenormand, P.; Ageron, E.; Grimont, P.A.D. (1995). Taxonomic diversity of anaerobic glycerol diSS1milation in the Enterobacteriaceae. Res. Microbiol. 146: 279-290.

7. da silva, G.P.; Mack, M.; Contiero, J. (2009). Glycerol: A promising and abundant carbon source for industrial microbiology. Biotechnol. Adv. 2: 30-39.

8. da Silva, G.P.; de Araújo, E.F.; Silva, D.O.; Guimarães, W.V. (2005). Ethanolic fermentation of sucrose, sugarcane juice and molasses by Escherichia coli strain KO11 and Klebsiella oxytoca strain P2. Braz. J. Microbiol. 36: 395-404.

9. Dharmadi, Y.; Murarka, A.; Gonzalez, R. (2006). Anaerobic fermentation of glycerol by Escherichia coli: a new platform for metabolic engineering. Biotechnol. Bioeng. 94: 821-829.

10. Durnin, G.; Clomburg, J.; Yeates, Z.; Alvarez, P.J.J.; Zygourakis, K.; Campbell, P.; Gonzalez, R. (2009). Understanding and HarneSS1ng the Microaerobic Metabolism of Glycerol in Escherichia coli. Biotechnol. Bioeng. 103: 1-14.

11. Hansen, A.C.; Zhang, Q.; Lyne, P.W.L. (2005). Ethanol-diesel Fuel Blends: A Review, Bioresour. Technol. 96: 277-288.

12. Hao, J.; Lin, R.; Zheng, Z.; Liu, H.; Liu, D. (2008). Isolation and characterization of microorganisms able to produce 1,3-propanediol under aerobic conditions. World J. Microbiol. Biotechnol. 24: 17311740 .

13. Himmi, E.H.; Bories, A.; Barbirato, F. (1999). Nutrient requirements for glycerol conversion to 1,3-propanediol by Clostridium butyricum. Bioresour. Technol. 67: 123-128.

14. Homann, T.; Tag, C.; Biebl, H.; Deckwer, W.D.; Schink, B. (1990). Fermentation of glycerol to 1,3- propanediol by Klebsiella and Citrobacter strains. Appl. Microbiol. Biotechnol. 33: 121-126.

15. Hu, H.; Wood, T.K. (2010). An evolved Escherichia coli strain for producing hydrogen and ethanol from glycerol. Biochem. Biophys. Res. Commun. 391: 1033-1038.

16. Huang, H.; Gong, C.S.; Tsao, G.T. (2002). Production of 1,3-propanediol by Klebsiella pneumoniae. Appl. Biochem. Biotechnol. 98: 687-698.

17. Ito, T.; Nakashimada, Y.; Senba, K.; Matsui, T.; Nishio, N. (2005). Hydrogen and ethanol production from glycerol-containing wastes discharged after biodiesel manufacturing process. J. Biosci. Bioeng. 100: 260-265.

18. Jarvis, G.N.; Moore, E.R.B.; Thiele, J.H. (1997). Formate and ethanol 
are the major products of glycerol fermentation produced by a Klebsiella planticola strain isolated from red deer. J. Appl. Microbiol. 83: 166-174

19. Kim, Y.; Ingram, L.O.; Shanmugam K.T. (2007). Construction of an Escherichia coli K-12 Mutant for Homoethanologenic Fermentation of Glucose or Xylose without Foreign Genes. Appl. Environ. Microbiol. 73: 1766-1771.

20. Lau, M.W.; Gunawan, C.; Balan, V.; Dale, B.E. (2010). Comparing the fermentation performance of Escherichia coli KO11, Saccharomyces cerevisiae 424A(LNH-ST) and Zymomonas mobilis AX101 for cellulosic ethanol production. Biotechnol. Biofuels. 3: 11-20.

21. Lee, P.C.; Lee, W.G.; Lee, S.Y.; Chang, H.N. (2001). Succinic acid production with reduced by-product formation in the fermentation of Anaerobiospirillum succiniciproducens using glycerol as a carbon source. Biotechnol. Bioeng. 72: 41-48.

22. Maeda, T.; Vardar, G.; Self, W.T.; Wood, T.K. (2007). Inhibition of hydrogen uptake in Escherichia coli by expreSS1ng the hydrogenase from the Cyanobacterium synechocystis sp. PCC 6803. BMC Biotechnol. 7: 25 .

23. Maeda, T.; Yoshimura, Y.; Shimazu, T.; Shirai, Y.; Ogawa, H.I. (2009). Enhanced production of lactic acid with reducing excess sludge by lactate fermentation. J. Hazard. Mater. 168: 656-663.
24. Malca, J.; Freire, F. (2006). Renewability and Life Cycle Energy Efficiencies of Bioethanol and Bioethyl Tertiary Butyl Ether: Assesing the Implications of Allocation. Energy. 31: 3362-3380.

25. Menzel, K.; Zeng, A.P.; Deckwer, W.D. (1997). Enzymatic evidence for an involvement of pyruvate dehydrogenase in the anaerobic glycerol metabolism of Klebsiella pneumoniae. J. Biotechnol. 56: 135-142.

26. Wang, Z.X.; Zhuge, J.; Fang, H.; Prior, B.A. (2001). Glycerol production by microbial fermentation: a review. Biotechnol. Adv. 19: 201-203.

27. Yazdani, S.S.; Gonzalez, R. (2007). Anaerobic fermentation of glycerol: a path to economic viability for the biofuels industry. Curr. Opin. Biotechnol. 18: 213-219.

28. Yazdani, S.S.; Gonzalez, R. (2008). Engineering Escherichia coli for the efficient conversion of glycerol to ethanol and co-products. Metabolic Engineering. 10: 340-351.

29. Zeng, A.P.; Biebl, H. (2002). Bulk chemicals from biotechnology: the case of 1,3-propanediol production and the new trends. Adv. Biochem. Eng. Biotechnol. 74: 239-259.

30. Zhu, M.M.; Lawman, P.D.; Cameron, D.C. (2002). Improving 1.3propanediol production from glycerol in a metabolically engineered Escherichia coli by reducing accumulation of sn-glycerol-3-phosphate. Biotechnol. Prog. 18: 694-699. 